\title{
Pembelajaran Sastra Berbasis Blended Learning
}

\author{
Eko Cahyo Prawoto1, Pana Pramulia² \\ ekocahyoprawoto@Ippi.unipa.ac.id, panapramulia@unipasby.ac.id \\ 1Program Studi Pendidikan Bahasa dan Sastra Indonesia \\ 2Program Studi Pendidikan Guru Sekolah Dasar \\ 1,2Universitas PGRI Adi Buana Surabaya
}

\begin{abstract}
Blended learning is one of the learning models applied in universities as an improvement in the quality of learning. Blended learning is a blend of two learning models, namely face-to-face learning and online learning / e-learning. Blended learning is used to stimulate and foster learning motivation for students, it is necessary to innovate and create more interesting media. Learning media that can be used in blended learning, namely flipbook software and auto play, through the two software instructors can create learning media through a combination of learning material in pdf, video (mp4), image (jpeg), ppt (pdf) and so on. Learning media that have been made uploaded in the classroom (google classroom) at the beginning of the lecture. Through google classroom students can download all learning media. With learning media that have been downloaded, students can learn more innovatively. In the media, the material presented is related to literary learning. Blended learning-based learning models can improve literary learning outcomes in Unipa Surabaya PBSI students in Literature Appreciation courses. The increase was due to the tendency of students to be more active, innovative, creative, and enthusiastic in independent learning, and in working on assignments given as evaluations in lectures with the learning media that had been provided.
\end{abstract}

Keywords: Blended Learning, Google Classroom, Literary Learning

\begin{abstract}
Abstrak
Blended learning merupakan salah satu model pembelajaran yang diterapkan di perguruan tinggi sebagai peningkatan mutu pembelajaran. Blended learning adalah perpaduan dua model pembelajaran, yaitu pembelajaran tatap muka dan pembelajaran online/e-learning. Blended learning digunakan untuk merangsang dan menumbuhkan motivasi belajar bagi peserta didik, maka perlu dilakukan inovasi dan kreasi media yang lebih menarik. Media pembelajaran yang dapat digunakan dalam pembelajaran blended learning, yaitu software flipbook dan auto play, melalui dua software tersebut pengajar dapat membuat media pembelajaran melalui kombinasi materi pembelajaran dengan format pdf, video (mp4), gambar (jpeg), ppt (pdf) dsb. Media pembelajaran yang sudah dibuat diunggah di ruang kelas (google classroom) diawal perkuliahan. Melalui google classroom peserta didik dapat mengunduh semua media pembelajaran. Dengan media pembelajaran yang sudah diunduh mahasiswa dapat belajar lebih inovatif. Di dalam media tersebut, materi yang disuguhkan berkaitan dengan pembelajaran sastra. Model pembelajaran berbasis blended learning dapat meningkatkan hasil belajar sastra pada mahasiswa PBSI Unipa Surabaya pada mata kuliah Apresiasi Sastra. Peningkatan tersebut, karena adanya kecenderungan peserta didik lebih aktif, inovatif, kreatif, serta antusias dalam belajar mandiri, dan dalam mengerjakan
\end{abstract}




\title{
Efektor, Volume 6 Issue 1, 2019, Pages 37 - 42 \\ Eko Cahyo Prawoto, Pana Pramulia
}

\begin{abstract}
tugas yang diberikan sebagai evaluasi dalam perkuliahan dengan media pembelajaran yang telah disediakan
\end{abstract}

Kata Kunci: Blended Learning, Google Classroom, Pembelajaran Sastra

\section{PENDAHULUAN}

Karya sastra tidak hanya dinikmati, tetapi membutuhkan apresiasi agar dapat berkembang. Apresiasi sastra membutuhkan kecakapan membaca untuk memahami karya sastra yang akan dinilai dan dikembangkan. Aminudin (2013:15) menyatakan usaha memahami unsur-unsur sastra harus dengan cara membaca. Maksudnya, proses membaca akan menumbuhkan reaksi kritis untuk memahami dan mendalami karya sastra yang diapresiasi. Berdasarkan hal tersebut, kecakapan membaca dibutuhkan agar penilaian yang dilakukan menjadi baik dan pengubahan bentuk karya sastra ke dalam bentuk lain dapat dinikmati oleh orang lain.

Salah satu mata kuliah wajib dalam Program Studi Pendidikan Bahasa dan Sastra Indonesia di Universitas PGRI Adi Buana Surabaya adalah Apresiasi Sastra. Apresiasi Sastra merupakan mata kuliah praktis yang di dalamnya memuat tiga jenis sastra, di antaranya puisi, prosa, dan drama. Tujuan dari mata kuliah ini, mahasiswa diharapkan dapat memberikan penilaian terhadap karya sastra secara sadar dan logis. Selain itu, hasil akhirnya mahasiswa dituntut mampu mengembangkan potensinya mengubah karya sastra tulis (puisi, prosa, dan drama) menjadi bentuk lain, seperti deklamasi puisi, seni drama, teatrikal, pantomim, film pendek, dan sebagainya. Karya sastra tulis yang diubah menjadi bentuk lain sedemikian rupa juga merupakan bentuk apresiasi terhadap karya sastra. Pertanyaannya: apakah mahasiswa saat ini memiliki keinginan, kemampuan, dan kecakapan membaca dan mengapresiasi?

Pertanyaan tersebut terjawab setelah peneliti melakukan survei kepada mahasiswa Pendidikan Bahasa dan Sastra Indonesia angkatan 2015 pada Rabu 5 April 2017. Angkatan 2015 saat ini masuk di semester 4. Survei dilakukan dengan cara memberi satu pertanyaan sama kepada seluruh mahasiswa angkatan 2015 dengan jumlah 122 mahasiswa. Pertanyaannya: Sudahkah Saudara membaca kumpulan puisi Aan Mansyur "Tidak Ada New York Hari Ini" dan kumpulan cerpen Aan Mansyur "Kukila"?. Dari 122 mahasiswa hanya 27 yang menjawab pernah. Artinya, mahasiswa Pendidikan Bahasa dan Sastra Indonesia yang seharusnya dekat dengan karya sastra hanya sebagian yang gemar membaca. Jumlah 27 yang membaca itupun, peneliti belum menguji kedalaman membaca masingmasing mahasiswa.

Padahal dua buku tersebut beserta penulisnya sangat populer di Indonesia saat ini, sebab beberapa puisi Aan Mansyur "Tidak Ada New York Hari Ini" digunakan dalam film Ada Apa Dengan Cinta 2. Hal tersebut menjadi ironi, karena mahasiswa Pendidikan Bahasa dan Sastra Indonesia sendiri belum membaca karya yang saat ini paling banyak dibicarakan tersebut. Di sisi lain, pembelajaran dan apresiasi yang dilakukan mahasiswa Pendidikan Bahasa dan Sastra Indonesia Universitas PGRI Adi Buana Surabaya monoton. Maksudnya, dari tahun ke tahun apresiasi yang dilakukan tidak menunjukkan perubahan signifikan, mengingat teknologi yang sudah berkembang sedemikian pesat tidak dimanfaatkan.

Maka dari itu, mata kuliah apresiasi sastra membutuhkan model pembelajaran yang atraktif dan kreatif agar mahasiswa dapat mengapresiasi karya sastra dengan baik sejalan dengan perkembangan teknologi saat ini. Model pembelajaran yang digunakan harus memiliki unsur modifikasi, misalnya kecakapan membaca dimodifikasi dengan model pembelajaran lain. Tujuannya, agar model pembelajaran lain dapat membantu mahasiswa mengatasi permasalahan membaca. Model pembelajaran yang digunakan harus memanfaatkan kecanggihan teknologi saat ini, agar dapat berpacu dengan perkembangan zaman.

Model pembelajaran yang digunakan yaitu Model Pembelajaran Blended Learning. Model pembelajaran tersebut dari kata "blended" merupakan penggabungan dua model pembelajaran. Bersin 


\section{Efektor, Volume 6 Issue 1, 2019, Pages 37 - 42 \\ Eko Cahyo Prawoto, Pana Pramulia}

(2004:15) menyatakan Blended Learning merupakan gabungan berbagai media dan peristiwa untuk program pelatihan yang bertujuan mengoptimalkan peserta didik agar lebih spesifik dalam proses pembelajaran. Media yang dimaksud berkaitan dengan teknologi, dimana saat ini teknologi, khususnya media berbasis internet digemari hampir semua kalangan masyarakat. Mayarakat pada umumnya dan mahasiswa khususnya tidak bisa dipisahkan dengan sumber informasi online. Artinya, model pembelajaran ini berbasis online sehingga mahasiswa melakukan proses pembelajaran melalui jalur virtual.

Selain itu, mahasiswa juga masih membutuhkan sistem pembelajaran tatap muka karena sebagai bahan pemahaman materi kuliah yang diajarkan. Pembelajaran tatap muka, selain untuk memahamkan materi dosen juga berkesempatan memberi motivasi membaca kepada mahasiswa. Seperti yang disebutkan sebelumnya, bahwa membaca begitu penting dalam proses apresiasi karya sastra. Jadi, Blended Learning merupakan metode belajar yang menggabungkan dua atau lebih metode dan pendekatan dalam pembelajaran untuk mencapai tujuan proses pembelajaran (Sutisna, 2016:158). Artinya, Blended Learning yang digunakan merupakan gabungan tiga model pembelajaran, yaitu pembelajaran berbasis virtual, pembelajaran tatap muka, dan mahasiswa memperdalam daya membacanya. Dalam pembelajaran blended learning terdapat istilah e-learning. E- learning adalah sistem pembelajaran yang memanfaatkan media elektronik sebagai alat untuk membantu kegiatan pembelajaran. Sebagaian, besar berasumsi bahwa elektronik yang dimaksud di sini lebih diarahakan pada penggunaan teknologi computer dan internet (Daryanto, 2015).

Berdasarkan uraian tersebut, penelitian ini akan mengembangkan model pembelajaran Blended Learning pada mata kuliah Apresiasi Sastra (prosa, puisi dan drama) mahasiswa Pendidikan Bahasa dan Sastra Indonesia Angkatan 2016 Univ. PGRI Adi Buana Surabaya. Hasil penelitian sementara, model pembelajaran Blended Learning dapat meningkatkan kualitas apresiasi mahasiswa terhadap karya sastra, karena dalam model ini ditawarkan berbagai macam media untuk mengembangkan potensi apresiasinya terhadap karya sastra. Selain itu, hasil akhir yang akan dicapai mahasiswa dapat mengubah bentuk karya sastra ke dalam bentuk lain dengan baik.

Rumusan masalah dalam penelitian ini, yaitu Bagaimana pengembangan model pembelajaran Blended Learning pada mata kuliah Apresiasi Sastra (prosa, puisi dan drama) mahasiswa Pendidikan Bahasa dan Sastra Indonesia Angkatan 2016 Univ. PGRI Adi Buana Surabaya? Sedangkan penelitian ini diharapkan dapat memberikan manfaat bagi mahasiswa dalam meningkatkan potensinya untuk memberikan apresiasi terhadap karya sastra, baik dari segi penilaian maupun dalam hal mengubah bentuk karya sastra ke dalam bentuk lain.

\section{METODE PENELITIAN}

Penelitian ini dilakukan di kampus I Univeritas PGRI Adi Buana Surabaya, yang terletak di Jl. Ngagel Dadi IIIB/37. Sedangkan subjek penelitian ini ialah mahasiswa Progam Studi Pendidikan Bahasa dan Sastra Indonesia Angkatan 2016 sejumlah 122 mahasiswa. Mahasiswa tersebut memprogram mata kuliah Apresiasi Sastra (prosa, puisi dan drama). Dalam penelitian ini digunakan model pengembangan ADDIE (Analysis - Desain - Develop - Implement - Evaluate). Model tersebut dipilih, sebab disesuaikan dengan kebutuhan dalam pengembangan model pembelajaran blended learning yang berorientasi pada produk dan implementasinya. Model ADDIE pertama kali dikembangan oleh Reiser dan Mollenda pada tahun 1990-an, model tersebut digunakan sebagai pedoman untuk membangun perangkat serta infrastruktur program pelatihan yang efektif serta dinamis sesaui dengan kebutuhan. Dalam perkembanganya model tersebut digunakan dalam pengembangan model pembelajaran. hingga saat ini banyak penelitian-penelitian yang menggunakan model tersebut sebagai pedoman pengembangan.

Untuk mengetahui tingkat menariknya produk (bahan pembelajaran; RPS, materi (PPT, artikel, literatur) serta media pembelajaran (visual, audio visual, website, classroom, video dII.), maka dilakukan serangkaian uji coba terhadap produk tersebut, lalu diadakan revisi apabila diperlukan. Uji coba 


\section{Efektor, Volume 6 Issue 1, 2019, Pages 37 - 42 \\ Eko Cahyo Prawoto, Pana Pramulia}

tersebut, antara lain uji coba satu satu, review ahli 1, uji coba kelompok kecil, review ahli 2, dan evaluasi.

Uji coba satu-satu terdiri dari 5 responden. Hasil dari uji ini kemudian dilakukan revisi dan hasil revisi ini digunakan untuk uji coba kelompok kecil (15 orang). Setelah produk pengembangan diuji coba, maka dilakukan review ahli yang terdiri dari ahli digitalisasi perangkat pembelajaran. Instrumen diberikan kepada kelompok kecil (15) responden. Tujuannya ialah apakah responden dapat menggukan bahan serta media pembelajaran yang dikembangan berbasis blended learning. Subyek uji coba dalam tahap ini sebanyak 15 responden. Setelah produk pengembangan disusun, maka dilakukan review ahli yang terdiri dari ahli digitalisasi perangkat pembelajaran. Pada terakhir akan dilakukan evaluasi pada keseluruhan produk yang telah digunakan, keberhasilan tersebut dapat dilihat pada tingkat pemahaman serta antusiasme mahasiswa. Selain itu, peneliti juga memberikan kuesioner kepada mahasiswa sebagai indikator keterpuasan dari pada produk yang dihasilkan.

\section{HASIL DAN PEMBAHASAN}

Blended learning terdiri dari kata "blended" (kombinasi/campuran) dan "learning" (belajar). Istilah lain yang sering digunakan adalah hybrid course (hybrid=campuran/kombinasi, course=mata kuliah) makna asli sekaligus yang paling umum blended learning mengacu pada belajar mongombinasikan atau mencampur antara pembalajaran tatap muka (face to face) dan pembelajaran berbasis komputer (online dan offline) (Dwiyogo, 2016:45).

Pada awal perkuliahan, peneliti yang sekaligus dosen mengkoordinasi mahasiswa untuk membuat google classroom. Seperti yang telah diuraikan, bahwa google classroom dibuat bertujuan untuk mengombinasi materi pembelajaran dengan format pdf, video (mp4), gambar (jpeg), ppt (pdf), dan sebagainya. Sebelum menguji coba google classroom, mahasiswa melakukan pretest untuk mengetahui seberapa dalam dan jauh pemahaman mereka tentang karya sastra.

Pertama yang dilakukan, yaitu menugasi mahasiswa untuk membaca Antologi Puisi karya Aaan Mansyur dengan judul "Tidak Ada New York Hari Ini". Puisi tersebut dipilih berdasarkan kepopuleran dan bahasa yang menyertainya. Peneliti menganggap, bahwa puisi-puisi Aan Mansyur

Hasil penilaian mahasiswa terhadap keseluruhan puisi yang terdapat dalam antologi "Tidak Ada New York Hari Ini" positif. Data yang diperoleh dari 122 mahasiswa, antara lain (a) 83 mahasiswa menilai bahwa puisi-puisi Aan Mansyur mudah dipahami, karena bahasa yang diuraikan tidak sulit; (b) 25 mahasiswa menilai, puisi-puisi yang terdapat dalam antologi "Tidak Ada New York Hari Ini" menceritakan tentang cinta dan bahasanya indah, maka mudah untuk dimengerti; (c) 14 mahasiswa menilai, puisi-puisi yang sudah dibacanya berkaitan dengan pengalaman pribadinya. Inti dari data yang sudah diperoleh tersebut menunjukkan bahwa mahasiswa menilai puisi-puisi Aan Mansyur yang terkumpul dalam antologi "Tidak Ada New York Hari Ini" menarik dan mudah dimengerti. Seperti yang telah dijelaskan pada latar belakang, bahwa puisi-puisi Aan Mansyur digunakan untuk mengisi film Ada Apa Dengan Cinta 2. Artinya, puisi-puisi tersebut populer dan mudah dikenali bagi siapa saja yang sudah menonton filmnya.

Langkah selanjutnya, mahasiswa diberi tugas untuk memaknai puisi-puisi yang terdapat dalam antologi "Tidak Ada New York Hari Ini". Hasil dari pemaknaan mahasiswa tidak sebaik penilaiannya. Artinya, mahasiswa belum terampil untuk mengkaji lebih dalam makna puisi, walaupun puisi yang dibaca terkesan mudah. Berikut merupakan salah satu contoh pemaknaan mahasiswa mengenai puisi yang berjudul 'Tidak Ada New York Hari Ini” bait Kedua.

Bahasa ibu adalah kamar tidurku

Kupeluk tubuh sendiri

Dan cinta - kau tak ingin aku

mematikan mata lampu (Mansyur, 2016:10)

Sebagian besar mahasiswa memaknai penggalan puisi di atas secara harafiah. Mahasiswa belum dapat mengaitkan antar baris. Selain itu, mahasiswa kesulitan memaknai keterkaitan antara 


\section{Efektor, Volume 6 Issue 1, 2019, Pages 37 - 42 \\ Eko Cahyo Prawoto, Pana Pramulia}

bahasa ibu dengan kamar tidurku, cinta dengan mematikan mata lampu. Bahasa ibu masih dimaknai sebagai bahasa ibunya sendiri (harafiah) dan kamar tidurku juga dimaknai sebagai kamar tidur secara harafiah.

Berdasarkan hal tersebut, dapat dikatakan bahwa sebagian besar mahasiswa belum dapat merasakan dan menikmati karya sastra. Artinya, mahasiswa hanya sekadar membaca sebagai hiburan tanpa mengambil makna dan nilai-nilainya. Maka, untuk meningkatkan kepekaan (rasa) mahasiswa terhadap karya sastra dibutuhkan media lain. Media yang digunakan bisa video atau suara (MP3) untuk merangsang kepekaan. Berikutnya, mahasiswa ditugasi untuk mencari video film "Ada Apa Dengan Cinta 2" di YouTube. Kemudian mencari penggalan video yang di dalamnya terdapat puisi yang berjudul "Tidak Ada New York Hari Ini". Langkah selanjutnya mahasiswa melakukan cutting video tersebut menggunakan VideoCutter. Dari penggalan video tersebut, mahasiswa diminta untuk menyimak berulang-ulang agar dapat menumbuhkan kepekaan dalam memaknai karya sastra.

Di sisi lain, dosen yang sekaligus peneliti menyiapkan pembelajaran berbasis online, yaitu melalui google classroom. Beberapa media, di antaranya video, MP3, File PDF, gambar dengan format jpg disiapkan dan diunggah di laman google classroom. File yang diunggah dapat diakses mahasiswa, baik di dalam kampus maupun di luar kampus. Untuk mengakses file dan mengunduh file di google classroom, mahasiswa menggunakan password yang sudah dibuatkan di awal pembelajaran. Mahasiswa juga dapat membaca tugas-tugas yang diberikan melalui laman tersebut. Tugas mahasiswa yang diunggah melalui google classroom juga mengombinasikan hasil pemaknaan puisi dengan media video, MP3, File PDF, dan gambar jpg. Antara mahasiswa satu dengan lainnya bisa saling menilai melalui ruang komentar. Kemudian dosen sebagai koordinator memberikan penguatan dan penilaian berdasarkan standar yang sudah ditentukan. Bagi mahasiswa yang tugasnya belum sesuai (berdasarkan penilaian mahasiswa dan dosen) dapat merevisi dan mengunggahnya kembali.

Pembelajaran berikutnya, dosen dan mahasiswa tatap muka untuk membahas kendala yang dialami, baik tentang permasalahan pemaknaan puisi, maupun teknis dan operasional google classroom. Semua mahasiswa tidak ada permasalahan tentang google classroom, bahkan berdasarkan kuisioner yang dibagikan mahasiswa tertarik. Melalui laman yang bernama google classroom ini, mahasiswa cenderung mudah untuk memaknai puisi, karena antara satu mahasiswa dengan lainnya bisa memberikan kritik, saran, dan masukan di ruang komentar. Hasil pemaknaan puisi yang diperoleh setelah mahasiswa mengoperasikan akun google classroom meningkat atau lebih baik dari sebelumnya. Akan tetapi, mahasiswa tetap membutuhkan pertemuan tatap muka untuk memperdalam pehamannya tentang materi maupun operasional google classroom. Selain itu, untuk mendukung peningkatan kemampuan mengoperasionalkan google classroom, secara individu mahasiswa diminta untuk belajar mengolah video, MP3, membuat gambar jpg, dan media lainnya.

Berdasarkan tugas yang diunggah di google classroom, kiranya pemahaman dan pemaknaan puisi yang dilakukan mahasiswa lebih baik. Pertama, selain membaca puisi melalui buku, mahasiswa juga merasakan suasana puisi melalui video (film). Kedua, mahasiswa bisa saling mengoreksi satu sama lain melalui laman google classroom. Ketiga, dosen menilai tugas secara online di laman google classroom dan mahasiswa bisa merevisi serta mengunggahnya kembali. Di sisi lain, media pembelajaran blended learning ini dapat digunakan mahasiswa untuk mentransformasikan karya sastra ke dalam bentuk lainnya dengan memanfaatkan aplikasi pembuat video atau AutoPlay. Sebelum melakukan tarnsformasi, mahasiswa berdiskusi berkelompok memaknai karya sastra yang akan diubah bentuknya. Hasil diskusi dibahas dalam pertemuan tatap muka, kemudian mahasiswa mengakses AutoPlay untuk proses transformasi.

Intinya, media pembelajaran berbasis blended learning dapat membantu mahasiswa untuk mudah berdiskusi satu sama lain tanpa pertemuan tatap muka. Selain itu, mahasiswa dapat saling mengoreksi, mengkritisi, dan memberikan saran kepada teman lainnya. Media pembelajaran blended learning selain efektif dijadikan ruang berdiskusi, juga menjadikan mahasiswa terampil dalam berteknologi. 


\section{Efektor, Volume 6 Issue 1, 2019, Pages 37 - 42 \\ Eko Cahyo Prawoto, Pana Pramulia}

\section{SIMPULAN}

Blended Learning merupakan gabungan berbagai media dan peristiwa untuk program pelatihan yang bertujuan mengoptimalkan peserta didik agar lebih spesifik dalam proses pembelajaran. Media yang dimaksud berkaitan dengan teknologi, dimana saat ini teknologi, khususnya media berbasis internet digemari hampir semua kalangan masyarakat. Pada umumnya, masyarakat dan mahasiswa khususnya tidak bisa dipisahkan dengan sumber informasi online. Artinya, model pembelajaran ini berbasis online sehingga mahasiswa melakukan proses pembelajaran melalui jalur virtual. Media pembelajaran berbasis blended learning dapat digunakan mahasiswa sebagai ruang berdiskusi secara online satu sama lain. Artinya, berdiskusi tanpa pertemuan tatap muka.

Selain itu, mahasiswa dapat saling mengoreksi, mengkritisi, dan memberikan saran kepada teman lainnya. Media pembelajaran blended learning selain efektif dijadikan ruang belajar bersama secara online, juga dapat dijadikan media untuk belajar terampil dalam berteknologi. Media pembelajaran blended learning ini dapat digunakan mahasiswa untuk mentransformasikan karya sastra ke dalam bentuk lainnya dengan memanfaatkan aplikasi pembuat video atau AutoPlay.

\section{DAFTAR PUSTAKA}

Aminudin. 2013. Pengantar Apresiasi Karya Sastra. Cetakan kesepuluh. Bandung: Sinar Baru Algesindo.

Bersin, Josh. 2004. The Blended Learning Book Best Practices, Proven Methodologies and Lesson Learned. San Fransisco: John Weley.

Daryanto. 2015. Media Pembelajaran. Bandung: PT. Sarana Tutorial Nurani Sejahtera.

Dwiyogo, Wasis D. 2016. Pembelajaran Berbasis Blended Learning. Malang: Wineka Media.

Mansyur, M. Aan. 2016. Tidak Ada New York Hari Ini. Jakarta: Gramedia Pustaka Utama.

Sutisna, Anan. 2016. Pengembangan Model Pembelajaran Blended Learning Pada Pendidikan Kesetaraan Program Paket $C$ dalam Meningkatkan Kemandirian Belajar. Jurnal Tekonologi Pendidikan Vol. 18, No. 3 Desember 2016. Jakarta: Universitas Negeri Jakarta. 